\title{
PARAMETRIC STUDY FOR E-SHAPED MICROSTRIP PATCH ANTENNA
}

\author{
Kim Huat Yeap ${ }^{1}$, Widad Ismail ${ }^{1}$, Soon Leng Yap ${ }^{2}$, Kim Ho Yeap ${ }^{3}$ \\ 1 Auto-ID Laboratory, School of Electrical \& Electronic Engineering, Universiti Sains Malaysia, Engineering \\ Campus, Seberang Perai Selatan, 14300 Nibong Tebal, Penang, Malaysia. \\ ${ }^{2}$ Motorola Solutions (M) Sdn. Bhd., Innoplex, No. 2A, Medan Bayan Lepas, Bayan Lepas Technoplex, Industrial \\ Park Mukim 12, S.W.D., 11900 Bayan Lepas, Pulau Pinang, Malaysia. \\ ${ }^{3}$ Dept. of Electronic Engineering, Faculty of Engineering and Green Technology, Universiti Tunku Abdul Rahman, \\ Jalan Universiti, Bandar Barat, 31900 Kampar, Perak, Malaysia.
}

Received: 28 Apr 2016 Revised : 28 Nov 2016 Accepted: 29 Nov 2016

\begin{abstract}
The 2.4-GHz ISM band is extensively adopted in wireless system networks. However, its band coverage depends on different country regulations. This paper presents an E-shaped patch antenna that operates in this ISM band and supports a dual resonance of $2.4 \mathrm{GHz}$ and $2.5 \mathrm{GHz}$. A parametric study of the antenna is conducted by varying the dimensions of its parameters in sequential accordance and the effect on its performance is analyzed. The result provides a comprehensive guidance for the design and optimization of the antenna. It also facilitates the adjustment of its resonant frequencies to comply with the respective country regulation.
\end{abstract}

\begin{abstract}
ABSTRAK Jalur ISM $2.4 \mathrm{GHz}$ dipakai secara meluas dalam rangkaian sistem tanpa wayar. Akan tetapi, liputan jalur ini bergantung pada peraturan-peraturan negara yang berlainan. Kertas ini menyampaikan sebuah antena tampalan yang beroperasi dalam jalur ISM dan menopang dwi resonans pada $2.4 \mathrm{GHz}$ dan $2.5 \mathrm{GHz}$. Kajian parametrik pada antena ini telah dikendalikan dengan mengubahkan dimensi parameternya mengikut urutan dan kesan pada prestasinya dianalisiskan. Keputusannya menyediakan suatu panduan yang menyeluruh bagi reka bentuk dan pengoptimuman antena ini. Ia juga mempermudahkan pelarasan frekuensi resonansnya agar mematuhi peraturan negara masing-masing.
\end{abstract}

Keywords: ISM band, E-shaped, microstrip patch antenna, parametric study, resonant frequencies

\section{INTRODUCTION}

In recent years, research works pertaining to the E-shaped microstrip patch antenna have been widely conducted, among which are listed in (Ang \& Chung, 2007; Bayat, 2012; Chen et al., 2010; Ghannay \& Samet, 2009; Islam et al., 2009a; Islam et al., 2009b; Jain et al., 2011; Jalali et al., 2014; Khidre et al., 2010; Pandey \& Vishvakarma, 2007; Razzaqi et al., 2013, Saha et al., 2013; Yang et al., 2001). This reactively-loaded antenna exhibits dualresonance on a single radiating structure, thereby omitting the need of separate antennas to support two different bands. Besides, it also renders antenna size reduction as well as bandwidth enhancement. This ultimately contributes to system compactness and cost effectiveness.

Albeit the many prominent features, it appears that to date, a complete study on its parametric behaviour is yet to require a rigorous treatment on the topic. In (Ghannay $\&$ Samet, 2009; Islam et al., 2009a; Islam et al., 2009b), for example, only the dimension of the inset slots is varied during its parametric study, whereas in (Pandey \& Vishvakarma, 2007; Yang et al., 2001), only the dimension and position of the inset slots are varied. (Ang \& Chung, 2007; Saha et al., 2013) carry out the parametric study only by varying the dimensions of the inset slots and center arm of the E-shaped patch. In (Bayat, 2012), the dimension and position of the inset slots as well as the dimension of the 
center arm are varied whereas in (Khidre et al., 2010), the dimension of the inset slots is varied along with the position of the feed point. (Jain et al., 2011) and (Jalali et al., 2014) conducted a brief study by only varying the dimension of the center arm and the length of the patch, respectively. On the other hand, (Razzaqi et al., 2013) presents a much detailed study by not only varying the dimensions of the inset slots and center arm, but also the width of the side arm as well as the position of its feed point. To the best of knowledge, it is noted that a full parametric study on the E-shaped antenna by varying every dimension within the geometry is not available in documentation. Yet, such study is in fact imperative, as each dimension is structurally inter-related and its surface current is continuously distributed throughout the patch as a whole.

In view of this fact, a comprehensive parametric study on the E-shaped microstrip patch antenna that operates in the $2.4-\mathrm{GHz}$ Industrial, Scientific and Medical (ISM) band is presented in this paper. The $2.4-\mathrm{GHz}$ ISM band is part of the radio frequency (RF) spectrum internationally reserved for research, industrial usages and for medical devices (International Telecommunication Union, 1947). It is governed by the International Telecommunication Union Radio (ITU-R) under the IEEE 802.11b/g/n standard (IEEE Computer Society, 2012). Due to the advantage of having license exemption in several major applications, this band has been extensively adopted in wireless technology mediums. These include Wireless Fidelity (Wi-Fi) networks, Bluetooth technology (Nazabal et al., 2012), video applications, RF identification devices (RFID), as well as microwave ovens and sulphur plasma lightings. Its usages span from 2.4 to $2.5 \mathrm{GHz}$, depending on country specific regulations (Coleman \& Westcott, 2012). In Japan, for instance, its allocated spectrum is from 2.471 to $2.497 \mathrm{GHz}$ while in the US and most European countries, the allowable bandwidth ranges from 2.4 to $2.4835 \mathrm{GHz}$. The relevant frequency allocation band for several countries is listed out in Table 1 (Zyren \& Petrick, 1999).

In this paper, the proposed E-shaped patch design resonates at both $2.4 \mathrm{GHz}$ and $2.5 \mathrm{GHz}$, so as to cover the entire $2.4-\mathrm{GHz}$ ISM band during its study. It is a multipleinput and multiple-output (MIMO) antenna that features three excitation ports to support multiple applications simultaneously. The center arm port resonates at $2.5 \mathrm{GHz}$ whereas both the side arm ports resonate at $2.4 \mathrm{GHz}$. An extensive study is conducted by systematically varying its geometrical parameters and the effect on its performance is analyzed. The effort is aimed at determining the relevance of the antenna resonance with its geometry. By gaining deeper insight on the resonance tendency, this study realizes a convenient way of tuning the antenna resonances to accommodate it into applications that comply with the respective country's permissible range.

Table 1. Frequency allocations at 2.4-GHz ISM band (Zyren \& Petrick, 1999).

\begin{aligned} & \hline Country Allocated Spectrum \\ & \hline US $2.4 \mathrm{GHz}-2.4835 \mathrm{GHz} \\ &$ Japan $2.471 \mathrm{GHz}-2.497 \mathrm{GHz} \\ &$ France $2.4465 \mathrm{GHz}-2.4835 \mathrm{GHz} \\ &$ Spain $2.445 \mathrm{GHz}-2.475 \mathrm{GHz} \\ &$\hline\end{aligned}




\section{ANTENNA DESIGN}

\subsection{Overview of Rectangular Patch Antenna}

The rectangular microstrip patch antenna could be visualized as two radiating slots separated by a transmission line (Munson, 1974). Its electric field propagates in a nonhomogeneous structure, whereby the

$$
\varepsilon_{\text {reff }}=\frac{\varepsilon_{r}+1}{2}+\frac{\varepsilon_{r}-1}{2}\left[1+12 \frac{h}{W}\right]^{-\frac{1}{2}}
$$

where $\varepsilon_{r}$ is the dielectric permittivity, $h$ is the height of the substrate, and $W$ is the width of the patch. $\varepsilon_{\text {reff }}$ is found slightly lower than $\varepsilon_{r}$ as the fringing fields around the periphery of the patch are not confined within the dielectric substrate alone but also spread into the air surroundings.

$$
\begin{gathered}
L=\frac{v_{o}}{2 f_{r} \sqrt{\varepsilon_{r e f f}}}-2 \Delta L \\
\Delta L=0.412 h \frac{\left(\varepsilon_{r}+0.3\right)\left(\frac{W}{h}+0.264\right)}{\left(\varepsilon_{r}-0.258\right)\left(\frac{W}{h}+0.8\right)}
\end{gathered}
$$

where $\Delta L$ is the fringing length at one edge of the patch and its width $(W)$ is expressed as (Kumar \& Gupta, 1985)

$$
W=\frac{v_{o}}{2 f_{r}} \sqrt{\frac{2}{\varepsilon_{r}+1}}
$$


where $v_{o}$ is the speed of light in free space $\left(3 \times 10^{11} \mathrm{~mm} / \mathrm{s}\right)$ while $f_{r}$ is the resonant frequency of the antenna.

The rectangular patch antenna field configuration differs with respect to its dimensions, as shown in Figure 1 (Balanis, 2005). When $L>W>h$, the dominant mode is $\mathrm{TM}_{010}$. When $L>W>\frac{L}{2}>h$ and $L>\frac{L}{2}>W>h$, its second order mode is $\mathrm{TM}_{001}$ and $\mathrm{TM}_{020}$, respectively. Similarly, when $W>L>h$, its dominant mode is $\mathrm{TM}_{001}$ and when $W>\frac{W}{2}>L>h$, its second order mode is $\mathrm{TM}_{002}$.

\subsection{Overview of E-Shaped Patch Antenna}

The E-shaped patch antenna is electrically loaded by inserting slots on a rectangular patch structure to tune its dual resonance effect. This could be represented by two inductor-capacitor (LC) tank circuits (Lee \& Chen, 1997). Its first resonance is exhibited by the original rectangular patch while its second resonance is caused by the slots then introduced. Figure 2(a) shows a rectangular patch that is represented by a single LC circuit, where current flows from the feeding point to both edges of the patch. The inductance $\left(L_{r}\right)$ is attributed to the current path length while the capacitance $\left(C_{r}\right)$ is mainly subjected to the sandwich-like structure of the substrate bounded by the patch and ground layers.

In Figure 2(b), two parallel slots are incorporated into the design, impacting a change of resonance (Ao \& Xiang, 2013). On the center of the patch, the current flows like the initial design, and hence it is modeled exactly as the original LC circuit. However at the sides of the patch, its current circumnavigates through the slots and the distance of its current path is increased. The effect of the increased path can be modeled as an additional series inductance $\left(\Delta L_{r}\right)$ (Kadu et al., 2012) while the slot inserted between the center and side of the patch results in an additional parallel capacitance $\left(\Delta C_{r}\right)$, hence, causing the side of the patch to resonate at a lower frequency (Patel \& Kosta, 2011).

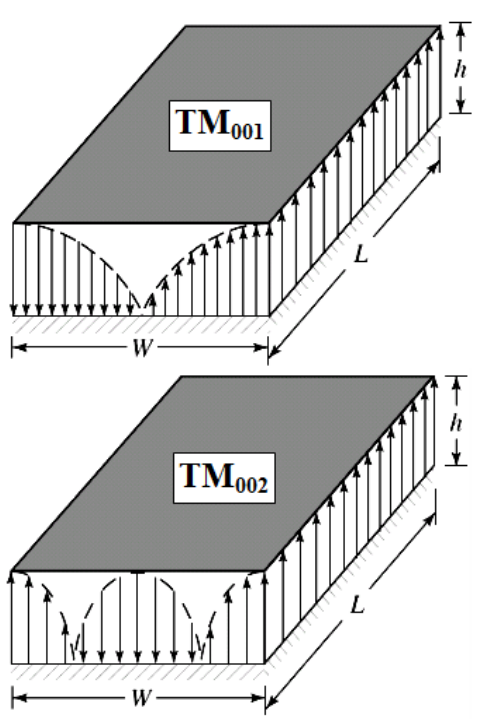

Figure 1. Different field configurations for a rectangular patch (Balanis, 2005). 

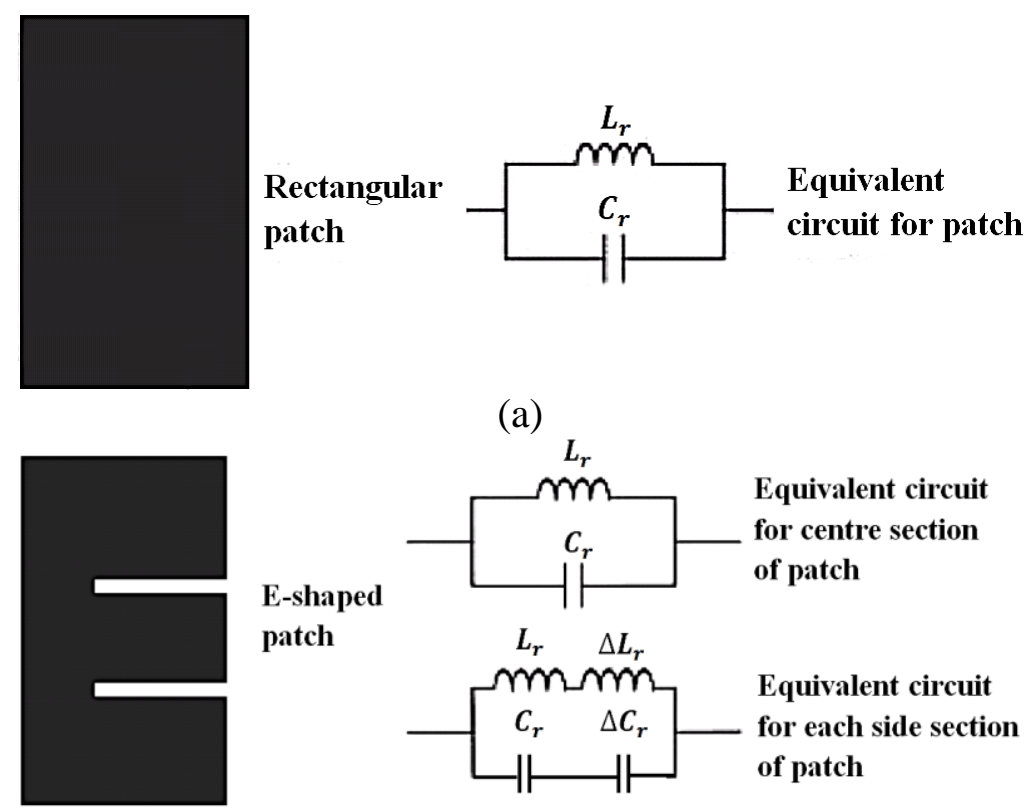

(b)

Figure 2. LC circuit of (a) rectangular patch and (b) E-shaped patch antenna (Lee \& Chen, 1997).

\subsection{Proposed E-Shaped Patch Antenna}

The proposed E-shaped patch antenna is shown in Figure 3. It is segmented into four sections, namely the dominant section $\left(S_{\text {dominant }}\right)$, the center section $\left(S_{\text {center }}\right)$, and two side sections $\left(S_{\text {side }}\right)$. In strict principle however, it is legitimately less appropriate to segment the antenna with a definite boundary, since the geometries of each section are structurally inter-related and its current is continuously distributed throughout as a whole. The segmentation in this context nevertheless, is solely intended to facilitate its parametric study and analysis.

$S_{\text {dominant }}$ plays the major part in the design, which is responsible for the overall radiation behaviour of the antenna. It determines the antenna resonance range and field configuration. $S_{\text {side }}$ and $S_{\text {center }}$ fine-tune $S_{\text {dominant }}$ to resonate at the desired frequencies with finer precision. Both these sections also function as transmission channels to interface the antenna with the external circuitries through its respective feeding point.

The proposed antenna is designed to resonate at $2.5 \mathrm{GHz}$ through $S_{\text {center }}$ and at 2.4 $\mathrm{GHz}$ through $S_{\text {side }}$. In other words, $f_{r}=2.5$ $\mathrm{GHz}$ is excited from Port 1 while $f_{r}=2.4$ $\mathrm{GHz}$ is excited from Port 2 and 3 each, referring to Figure 3. The upshot design simulated using Advanced Design System (ADS) Momentum is shown in Figure 4(a) and 4(b), while its dimensions are listed in Table 2. The patch is then fabricated on a Flame-Retardant level 4 (FR-4) substrate with $\varepsilon_{r}=4.5$ and $h=1.6 \mathrm{~mm}$, as shown in Figure 4(c). The bandwidth of the antenna is evaluated base on its $10 \mathrm{~dB}$ return loss (RL). That is to say, the magnitude of reflection coefficient $(|\Gamma|)$ in $\mathrm{dB}$, corresponding to the resonance at each port has to be less than -10 $\mathrm{dB}$, given as 


$$
\left\{\begin{array}{cc}
S 11<-10 d B, & f_{r}=2.5 G H z \\
S 22, S 33<-10 d B, & f_{r}=2.4 G H z
\end{array}\right.
$$

Its measured and simulated $|\Gamma|$ (in $\mathrm{dB}$ ) plotted across $2.2 \mathrm{GHz}$ to $2.8 \mathrm{GHz}$ is shown in Figure 5. The notches for both plots simultaneously dip about its respective frequency of interest, that is $2.5 \mathrm{GHz}$ for $\mathrm{S} 11,2.4 \mathrm{GHz}$ for $\mathrm{S} 22$ and S33. With a deviation of less than $4 \mathrm{~dB}$, the simulation results are deemed closely co-related to the physical board performance. Besides, the design exhibits substantial $50 \Omega$ matching at its respective port of interest as evident by the $\mathrm{S}$-parameters response below the red line $(-10 \mathrm{~dB})$ in the plot. The measured $\mathrm{S} 11$ is $16.175 \mathrm{~dB}$ at $2.5 \mathrm{GHz}$, while $\mathrm{S} 22$ is -17.497 $\mathrm{dB}$ and $\mathrm{S} 33$ is $-18.592 \mathrm{~dB}$, at $2.4 \mathrm{GHz}$. From the simulation, $\mathrm{S} 11$ is $-13.347 \mathrm{~dB}$ at 2.5
$\mathrm{GHz}$, while $\mathrm{S} 22$ is $-16.546 \mathrm{~dB}$ and $\mathrm{S} 33$ is $16.553 \mathrm{~dB}$, at $2.4 \mathrm{GHz}$.

It is further observed that at Port 1, the measured $10-\mathrm{dB}$ bandwidth ranges from 2.47 to $2.552 \mathrm{GHz}$, while at Port 2 from 2.372 to $2.42 \mathrm{GHz}$ and Port 3 from 2.373 to $2.421 \mathrm{GHz}$. This infers that at Port 1, its bandwidth is $82 \mathrm{MHz}$ while at Port 2 and 3, it is each $48 \mathrm{MHz}$. On the other hand, the ADS Momentum simulated frequency range covers a bandwidth of $76 \mathrm{MHz}$ from 2.469 to $2.545 \mathrm{GHz}$ at Port 1. At each Port 2 and 3, the simulated bandwidth is $68 \mathrm{MHz}$, which ranges from 2.361 to $2.429 \mathrm{GHz}$.

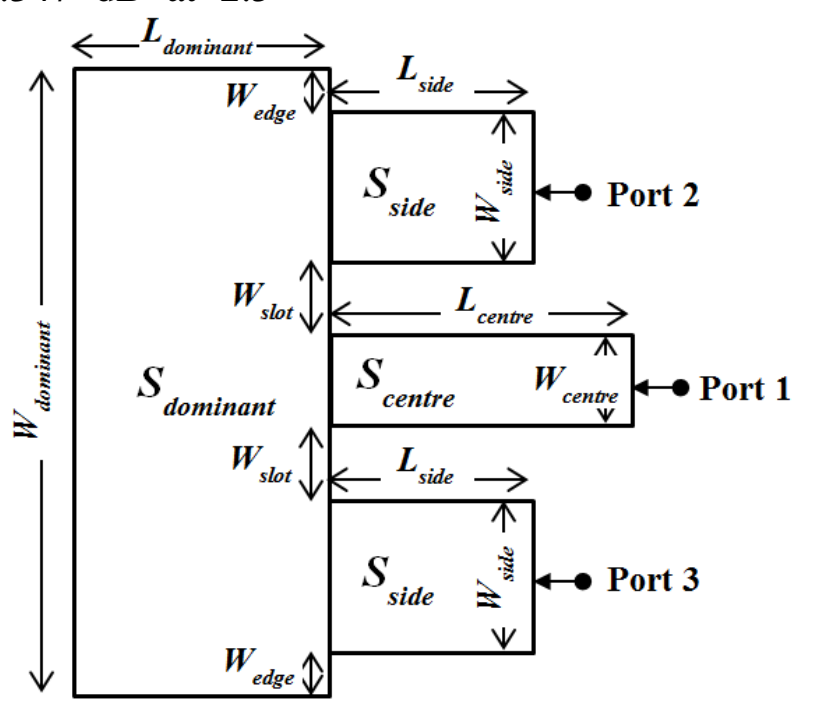

Figure 3. Proposed E-shaped patch antenna. 


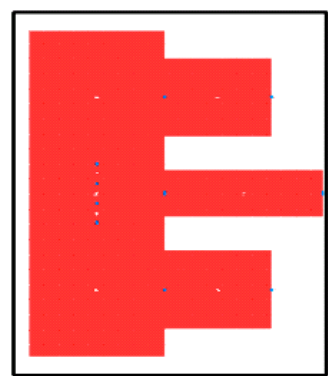

(a)

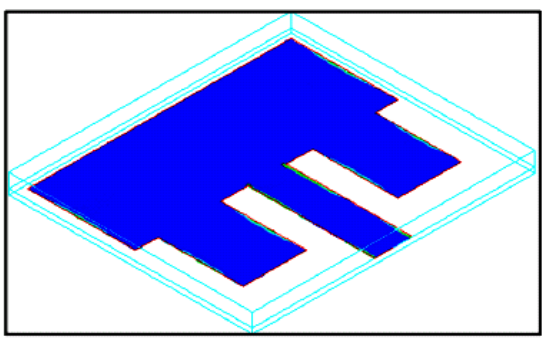

(b)

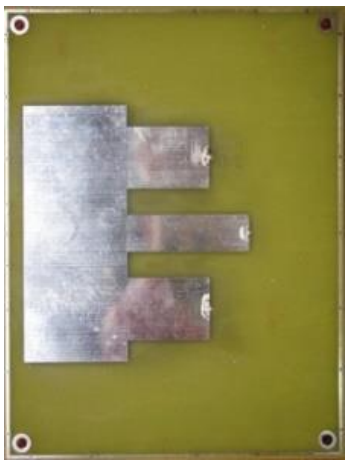

(c)

Figure 4. (a) Top, (b) isometric views of simulated design, and (c) prototype board of E-shaped antenna.

Table 2. Dimensions of E-shaped patch antenna.

\begin{tabular}{clc}
\hline Segments & Parameters & Dimensions \\
\hline \multirow{2}{*}{$S_{\text {dominant }}$} & $W_{\text {dominant }}$ & $83.00 \mathrm{~mm}$ \\
& $L_{\text {dominant }}$ & $34.00 \mathrm{~mm}$ \\
\hline \multirow{2}{*}{$S_{\text {center }}$} & $W_{\text {center }}$ & $12.00 \mathrm{~mm}$ \\
\multirow{2}{*}{$S_{\text {side }}$} & $L_{\text {center }}$ & $40.00 \mathrm{~mm}$ \\
\hline \multirow{2}{*}{ Slots/Slits } & $W_{\text {side }}$ & $20.00 \mathrm{~mm}$ \\
& $L_{\text {side }}$ & $27.00 \mathrm{~mm}$ \\
\hline & $W_{\text {slot }}$ & $8.50 \mathrm{~mm}$ \\
& $W_{\text {edge }}$ & $7.00 \mathrm{~mm}$ \\
\hline
\end{tabular}

It is to be noted that the resemblance in response for both S22 and S33 is absolutely non-coincidental. In fact, this manifestation could be well explicated from the dimensions of $S_{\text {dominant }}$ From Table 2, $W_{\text {dominant }}>\frac{W_{\text {dominant }}}{2}>L_{\text {dominant }}>h$, whereby $W_{\text {dominant }}$ and $L_{\text {dominant }}$ is the respective width and length of $S_{\text {dominant }}$. The antenna thus operates in the $\mathrm{TM}_{002}$ mode configuration. As evident in Figure 1, the field propagation is identical at both ends along the width, $W_{\text {dominant }}$. Consequently, with the signals channeled through $S_{\text {side }}$ 's from both ends of $W_{\text {dominant }}$, Port 2 and 3 inherit a similar degree of output matching.
The ADS Momentum simulated current distribution of the proposed antenna is shown in Figure 6(a), where the current in the center and sides of the patch crosses over each other while meandering along the slots. Its simulated current density presented in Figure 6(b) shows a much intense current flow in the center compared to both its edges, a physical interpretation of its dualresonance effect. The antenna threedimensional (3D) radiation pattern is also visualized in Figure 6(c), which portrays a broadside radiation, as customary for microstrip patch antenna. 


\section{PARAMETRIC STUDY}

The parametric study of the proposed antenna is conducted in simulation by systematically varying the segmented dimensions of each parameter designated in Figure 3. Its corresponsive $|\Gamma|$ responses (in $\mathrm{dB})$ are studied and discussed.

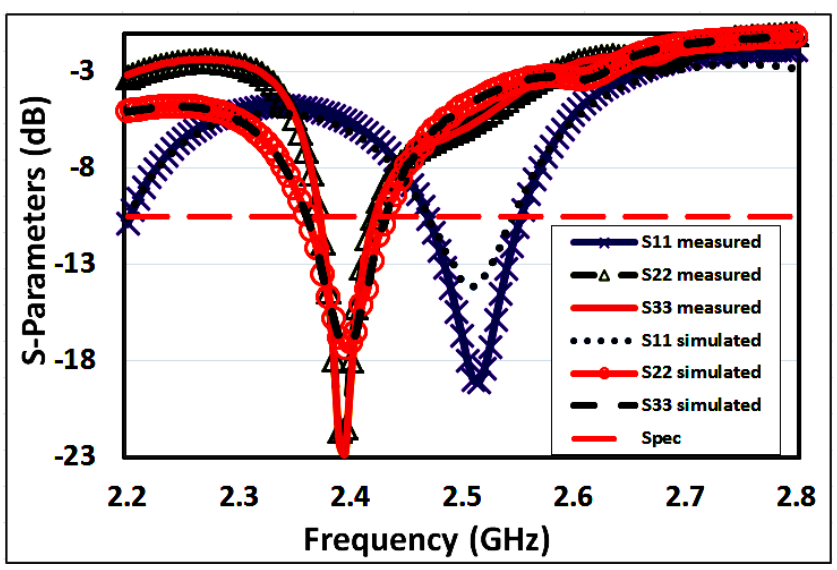

Figure 5. Reflection coefficient responses for the proposed E-shaped antenna.

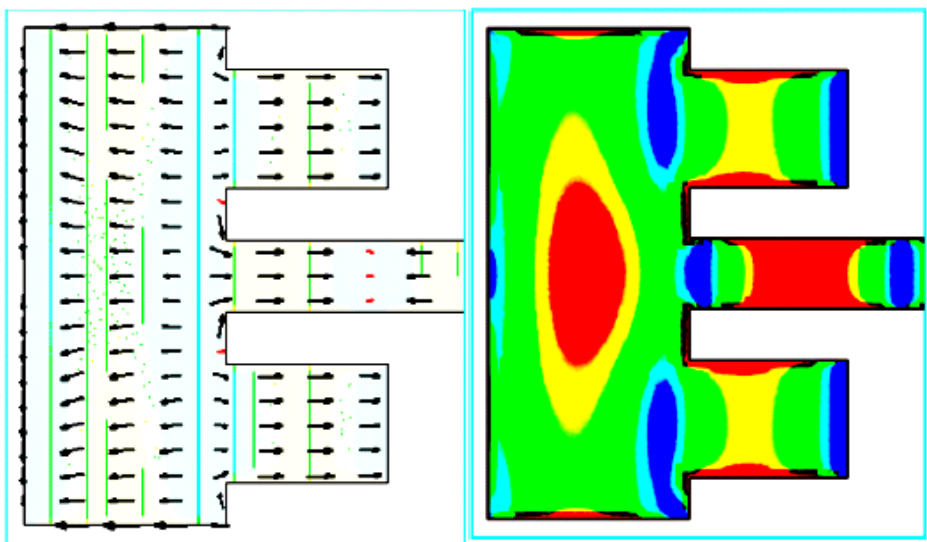

(a)

(b)

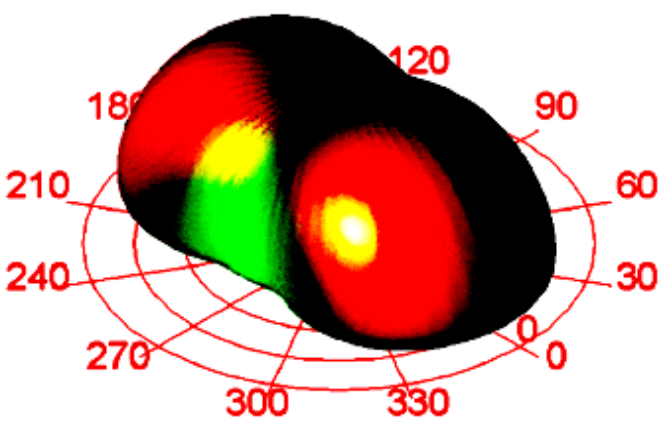

(c)

Figure 6. (a) Current distribution, (b) current density, and (c) 3D radiation pattern of the proposed E-shaped antenna. 


\subsection{Dominant Section $\left(S_{\text {dominant }}\right)$}

$W_{\text {dominant }}$ is expanded by every $4 \mathrm{~mm}$ from $75 \mathrm{~mm}$ to $91 \mathrm{~mm}$ while the dimensions of the remaining parameters are the same as in Table 2. Its $|\Gamma|$ responses (in $\mathrm{dB}$ ) are plotted in Figure 7. As the width expands, a reduction of spacing between both optimal resonances is observed from $127 \mathrm{MHz}$ to $109 \mathrm{MHz}$, as shown in Figure 7(a). This 18 $\mathrm{MHz}$ spacing reduction indicates that both resonances grow closer as $W_{\text {dominant }}$ widens. At the meantime, the high resonant frequency at Port 1 as well as the low resonant frequency at Port 2 and 3 also decrease. In Figure 7(b), the optimal high resonant frequency at Port 1 decreases from $2.565 \mathrm{GHz}$ to $2.483 \mathrm{GHz}$ with its corresponding S11 decreases much from $9.913 \mathrm{~dB}$ to $-16.083 \mathrm{~dB}$. This decrease signifies an improvement in the degree of output matching at Port 1. Concurrently, the optimal low resonant frequency at Port 2 and 3 , respectively decreases from $2.438 \mathrm{GHz}$ to $2.374 \mathrm{GHz}$, as mutually displayed in Figure 7(c) and (d). Nevertheless, the S22 and S33 responses are considerably consistent.
Similarly, $L_{\text {dominant }}$ is varied from 32 $\mathrm{mm}$ to $36 \mathrm{~mm}$ by an interval of $1 \mathrm{~mm}$ while keeping the dimensions of $W_{\text {dominant }}$ and the rest of the parameters the same as in Table 2. The frequency spacing between the optimal resonances increases notably from $75 \mathrm{MHz}$ to $151 \mathrm{MHz}$, as shown in Figure 8(a). This spacing increase of $76 \mathrm{MHz}$ simply implies that both frequencies resonate further away from each other as $L_{\text {dominant }}$ lengthens. In conjunction to this, the high resonant frequency at Port 1 as well as the low resonant frequency at Port 2 and 3 experience a decrease. In Figure 8(b), the optimal high resonant frequency at Port 1 decreases from $2.558 \mathrm{GHz}$ to $2.465 \mathrm{GHz}$ while in both Figure 8(c) and (d), the optimal low resonant frequency at Port 2 and 3 respectively decreases from $2.483 \mathrm{GHz}$ to $2.314 \mathrm{GHz}$. Despite the decrease in its resonances, the $|\Gamma|$ (in $\mathrm{dB}$ ) at all three ports increase as $L_{\text {dominant }}$ increases. At Port 1 , its optimal S11 increases from $-18.9 \mathrm{~dB}$ to $11.25 \mathrm{~dB}$ while at Port 2, its optimal S22 increases from $-20.216 \mathrm{~dB}$ to $-15.28 \mathrm{~dB}$ and at Port 3, its optimal S33 increases from $20.212 \mathrm{~dB}$ to $-15.282 \mathrm{~dB}$.

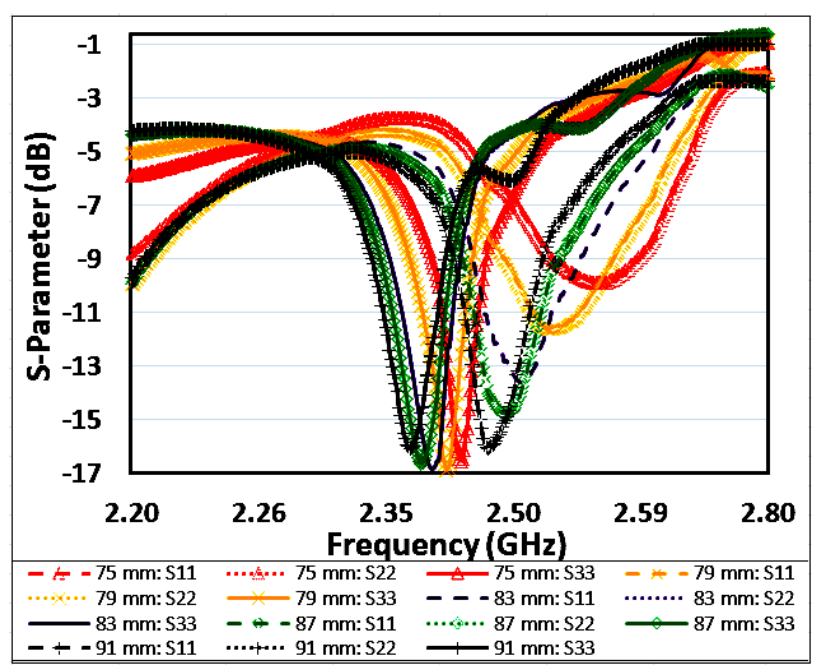

(a) 


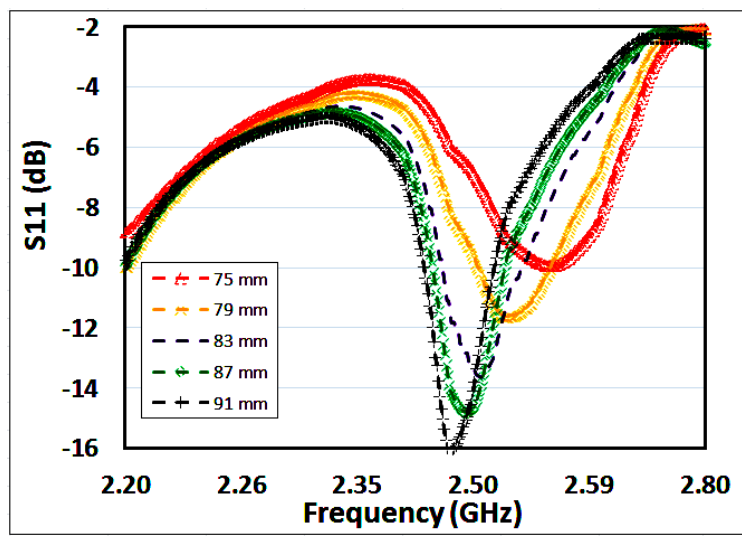

(b)

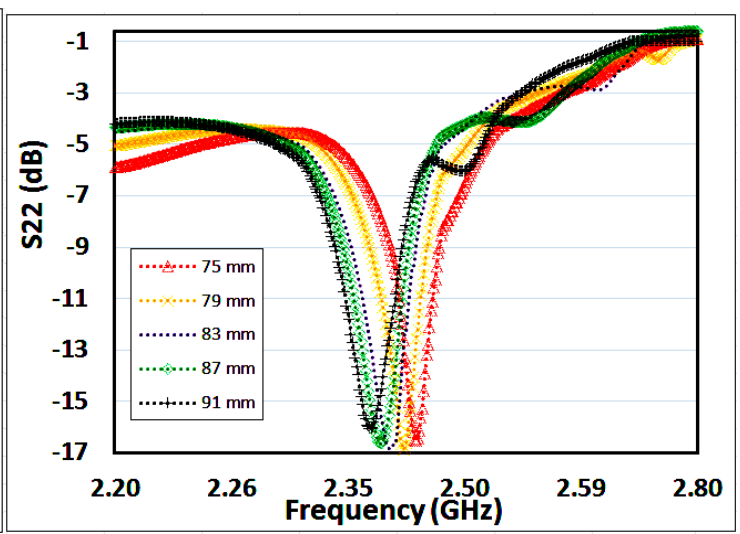

(c)

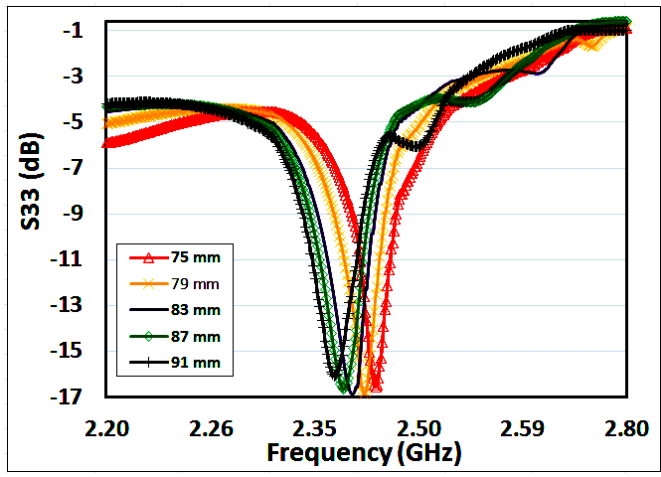

(d)

Figure 7. (a) $|\Gamma|$ responses (in $\mathrm{dB}$ ) and (b) $\mathrm{S} 11$, (c) $\mathrm{S} 22$, (d) $\mathrm{S} 33$ responses, as $W_{\text {dominant }}$ varies from $75 \mathrm{~mm}$ to $91 \mathrm{~mm}$.

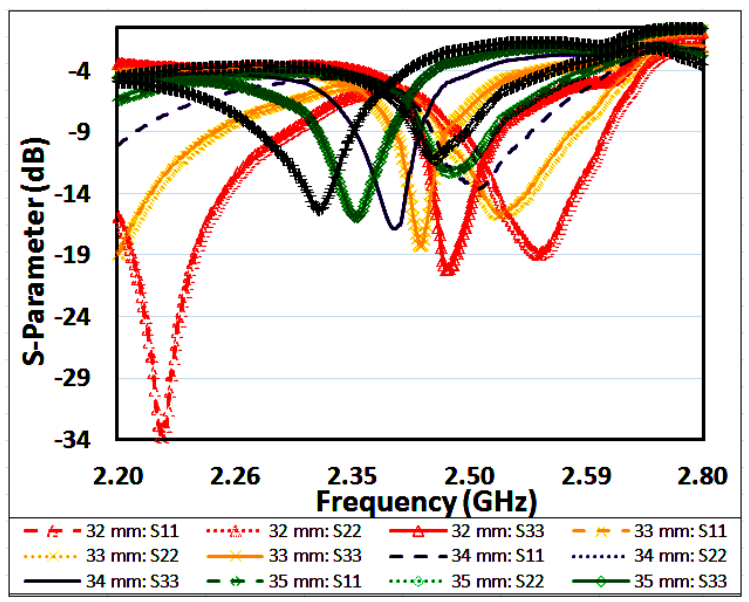

(a) 

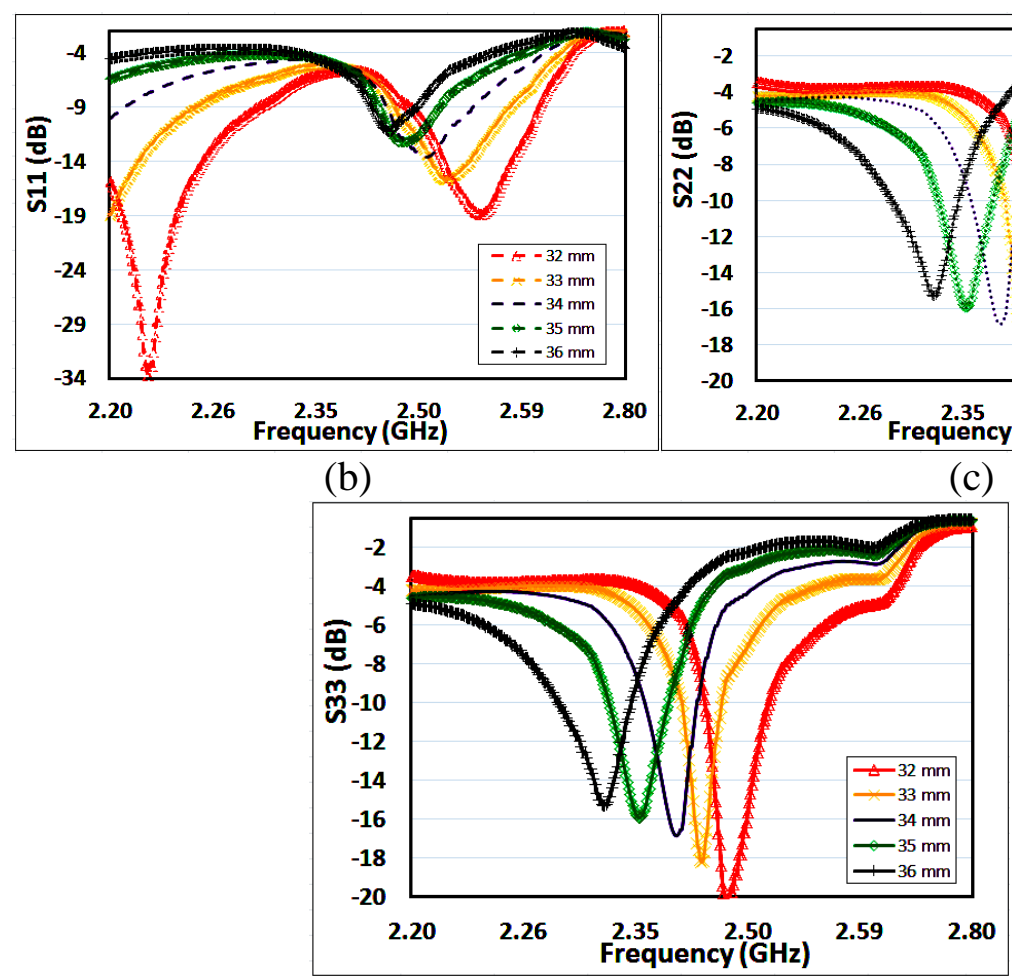

(d)

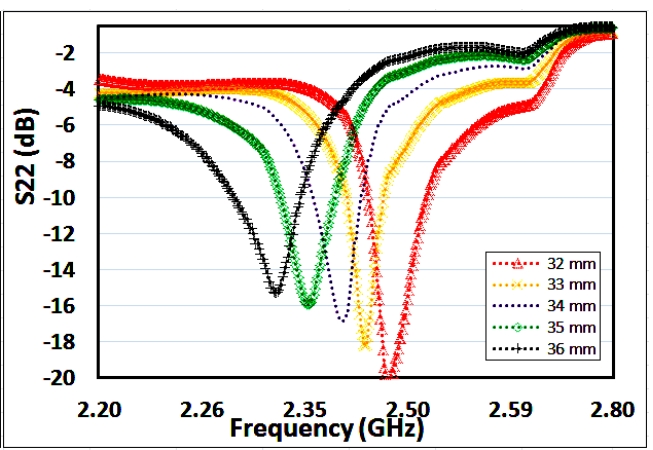

(c)

Figure 8. (a) $|\Gamma|$ responses (in dB) and (b) S11, (c) S22, (d) S33 responses, as $L_{\text {dominant }}$ varies from $32 \mathrm{~mm}$ to $36 \mathrm{~mm}$.

\subsection{Side Section $\left(S_{\text {side }}\right)$}

The width of $S_{\text {side }}\left(W_{\text {side }}\right)$ is expanded by every $1 \mathrm{~mm}$ from $18 \mathrm{~mm}$ to $22 \mathrm{~mm}$ while the dimensions of the rest of the parameters are maintained as in Table 2. Its corresponding $|\Gamma|$ responses (in $\mathrm{dB}$ ) are plotted in Figure 9. As the width expands, a small reduction of spacing between both optimal resonances is observed from 119 $\mathrm{MHz}$ to $108 \mathrm{MHz}$, as shown in Figure 9(a). The spacing reduction of merely $11 \mathrm{MHz}$ indicates that both resonances are slowly tuned closer as $W_{\text {side }}$ widens. Meanwhile, the resonances at all three ports increase much gradually. In Figure 9(b), the optimal high resonant frequency at Port 1 is almost constant. To be exact, the insignificant increase is only $6 \mathrm{MHz}$ from $2.505 \mathrm{GHz}$ to $2.511 \mathrm{GHz}$. In Figure 9(c) and (d) respectively, the optimal low resonant frequency at Port 2 and 3 increases a little from $2.386 \mathrm{GHz}$ to $2.403 \mathrm{GHz}$. On the other hand, the $|\Gamma|$ (in $\mathrm{dB}$ ) at all three ports experience an insignificant increase. At Port 1, its optimal S11 increases from $-14.03 \mathrm{~dB}$ to $-13.333 \mathrm{~dB}$ while at Port 2 , its optimal $\mathrm{S} 22$ increases from $-17.274 \mathrm{~dB}$ to -16.358 $\mathrm{dB}$ and at Port 3, its optimal S33 increases from $-17.278 \mathrm{~dB}$ to $-16.357 \mathrm{~dB}$.

Similarly, the length of $S_{\text {side }}\left(L_{\text {side }}\right)$ is varied from $23 \mathrm{~mm}$ to $31 \mathrm{~mm}$ by an interval of $2 \mathrm{~mm}$ while keeping the dimensions of $W_{\text {side }}$ and the rest of the parameters the same as in Table 2. Its $|\Gamma|$ responses (in $\mathrm{dB}$ ) are plotted in Figure 10. The frequency spacing between its optimal resonances increases significantly for $132 \mathrm{MHz}$, from $52 \mathrm{MHz}$ to $184 \mathrm{MHz}$, as shown in Figure 10(a). This apparently implies that both frequencies resonate much further away from each other 
as $L_{\text {side }}$ lengthens. In conjunction to this, the $|\Gamma|$ (in $\mathrm{dB}$ ) at all three ports increase. In Figure 10(b), the optimal high resonant frequency at Port 1 decreases from 2.555 $\mathrm{GHz}$ to $2.475 \mathrm{GHz}$ but its corresponding S11 increases remarkably from $-31.756 \mathrm{~dB}$ to $-10.158 \mathrm{~dB}$. Meanwhile, Figure 10(c) and (d) show that the optimal low resonant frequency at each Port 2 and 3 decreases greatly from $2.503 \mathrm{GHz}$ to $2.291 \mathrm{GHz}$. Its corresponding S22 increases from -20.824 $\mathrm{dB}$ to $-15.792 \mathrm{~dB}$ while its corresponding S33 increases from $-20.823 \mathrm{~dB}$ to -15.789 dB.

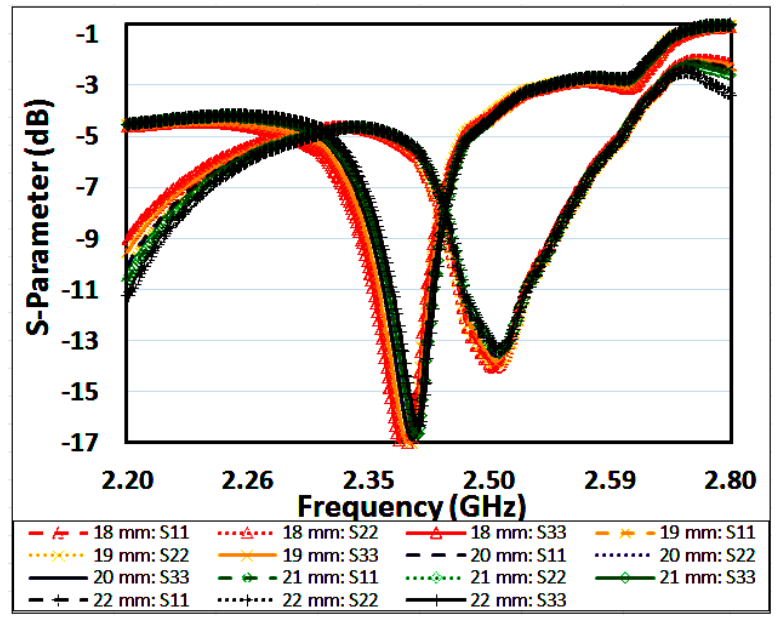

(a)

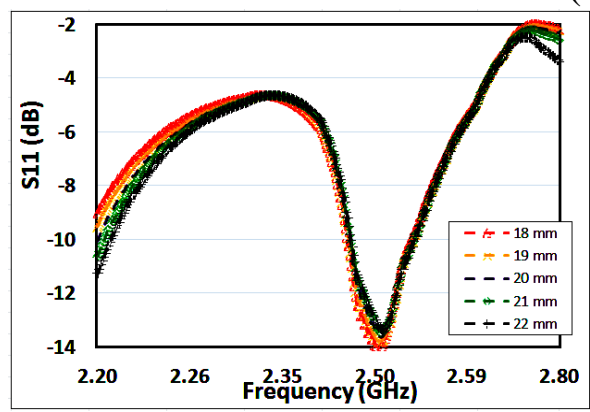

(b)

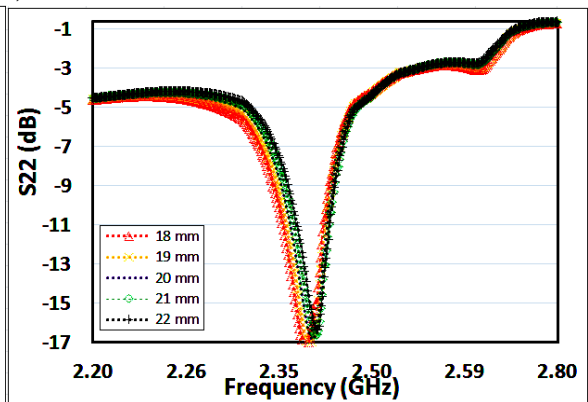

(c)

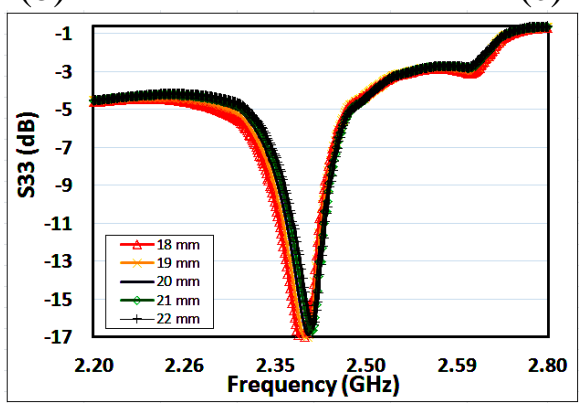

(d)

Figure 9. (a) $|\Gamma|$ responses (in $\mathrm{dB}$ ) and (b) $\mathrm{S} 11$, (c) $\mathrm{S} 22$, (d) $\mathrm{S} 33$ responses, as $W_{\text {side }}$ varies from $18 \mathrm{~mm}$ to $22 \mathrm{~mm}$. 

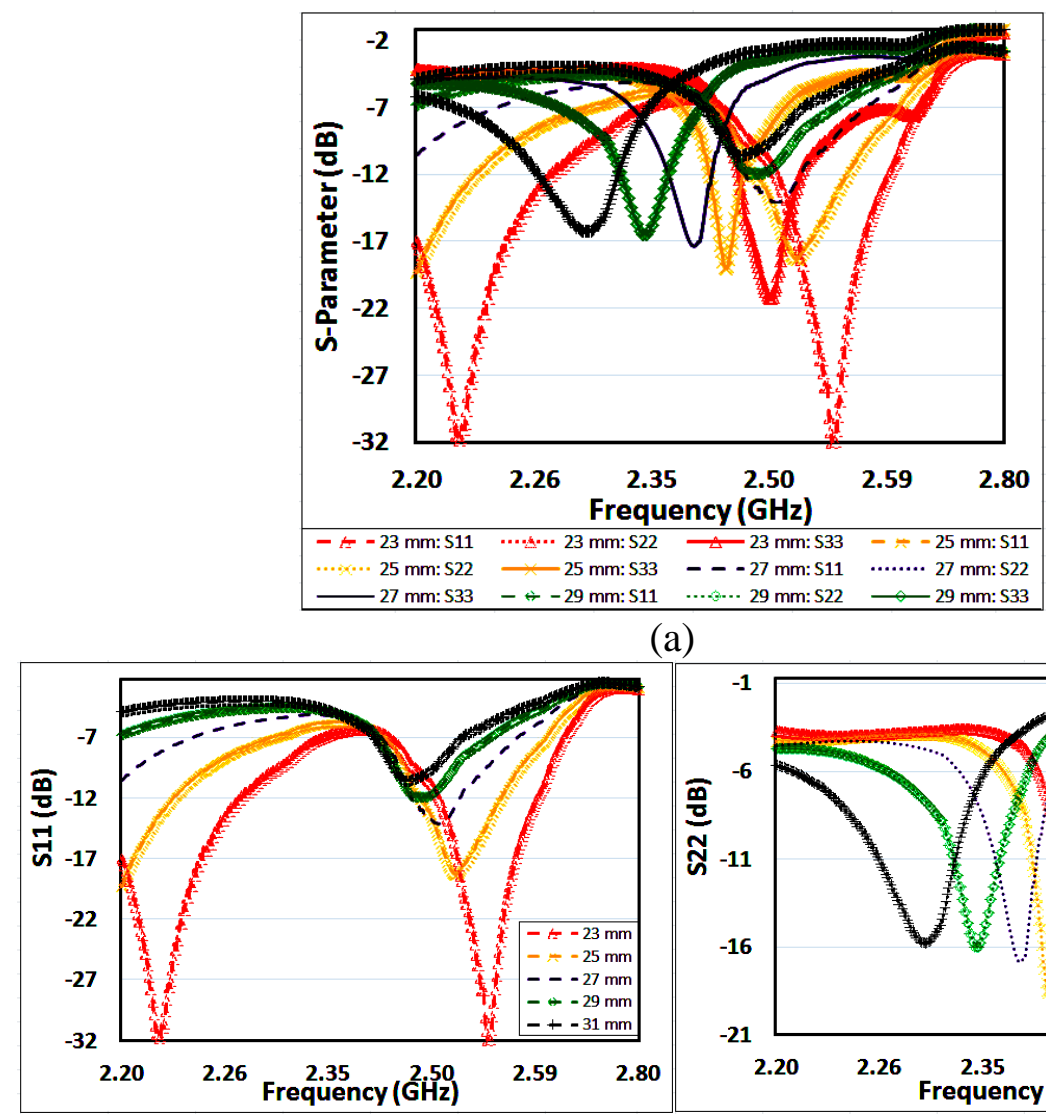

(a)

(b)
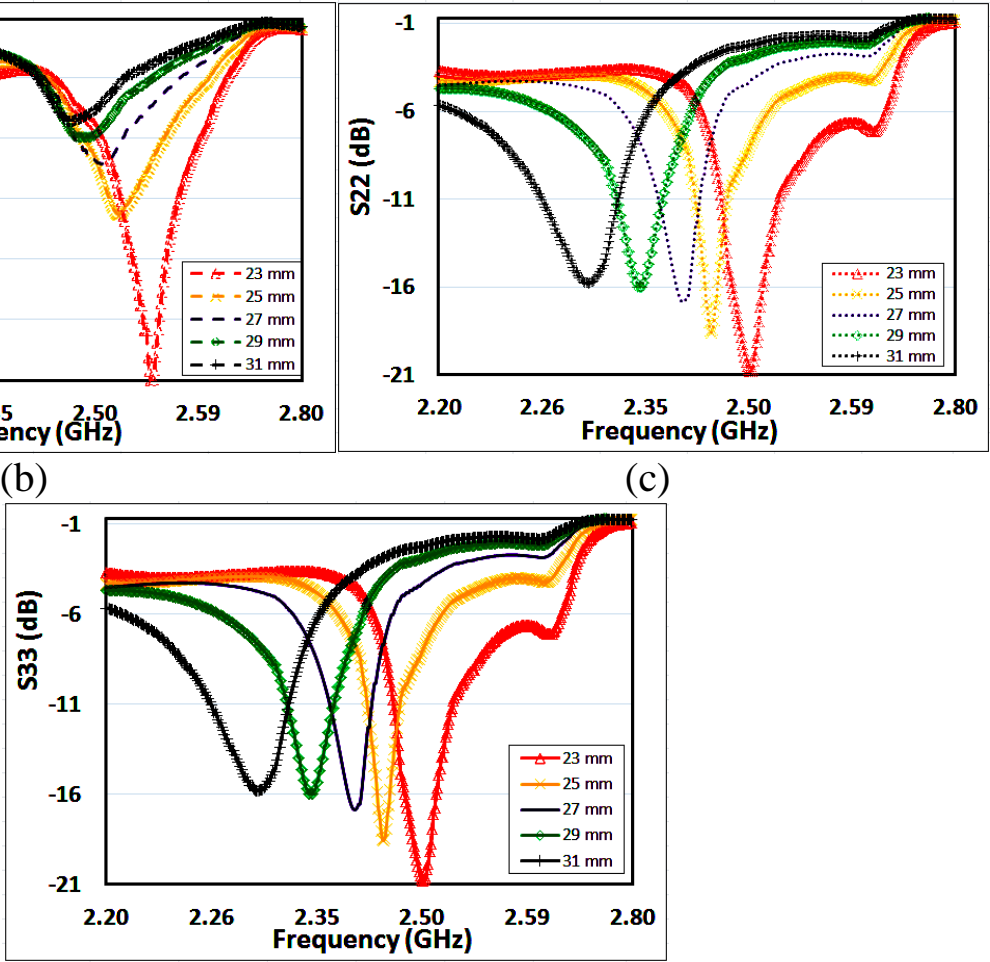

(d)

Figure 10. (a) $|\Gamma|$ responses (in $\mathrm{dB}$ ) and (b) $\mathrm{S} 11$, (c) $\mathrm{S} 22$, (d) $\mathrm{S} 33$ responses, as $L_{\text {side }}$ varies from $23 \mathrm{~mm}$ to $31 \mathrm{~mm}$.

\subsection{Center Section $\left(S_{\text {center }}\right)$}

The width of $S_{\text {center }}\left(W_{\text {center }}\right)$ is expanded by every $1 \mathrm{~mm}$ from $10 \mathrm{~mm}$ to $14 \mathrm{~mm}$. The dimensions of the rest of the parameters remain the same as in Table 2. Its corresponding $|\Gamma|$ responses (in $\mathrm{dB}$ ) are shown in Figure 11. In Figure 11(a), it is observed that both optimal resonances grow closer to each other with spacing from 127 $\mathrm{MHz}$ to $109 \mathrm{MHz}$ as $W_{\text {center }}$ widens. It is also observed from Figure 11(b) that at Port 1, its optimal high resonant frequency decreases gradually by $15 \mathrm{MHz}$ from $2.519 \mathrm{GHz}$ to 
2.504 GHz with $\mathrm{S} 11$ reduces from -10.076 $\mathrm{dB}$ to $-18.822 \mathrm{~dB}$. On the other hand, Figure 11(c) and (d) indicates that the low resonant frequency at Port 2 and 3 are relatively constant. To be precise, its optimal resonance increases very little by only 7 $\mathrm{MHz}$ from $2.392 \mathrm{GHz}$ to $2.399 \mathrm{GHz}$, with S22 increases slightly from $-17.046 \mathrm{~dB}$ to $16.627 \mathrm{~dB}$ and $\mathrm{S} 33$ from $-17.039 \mathrm{~dB}$ to $16.626 \mathrm{~dB}$.

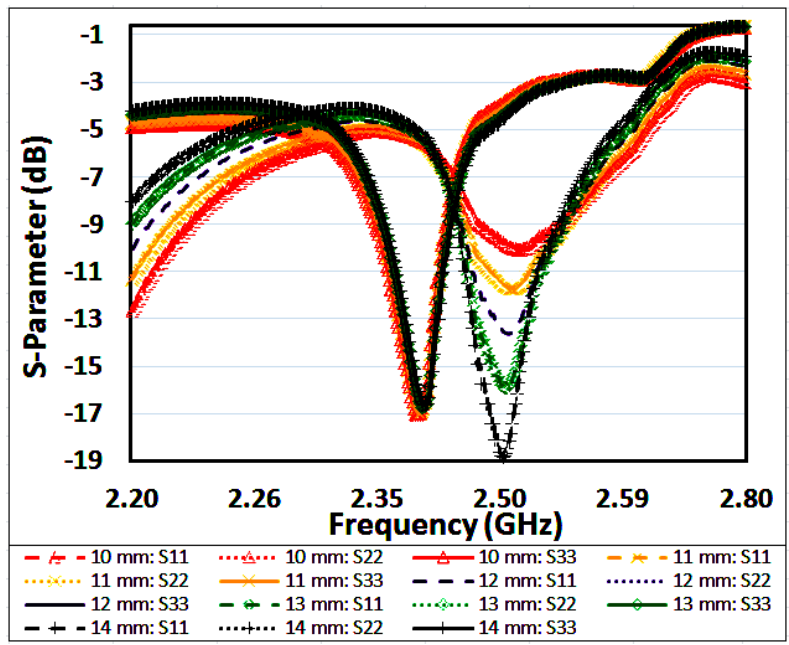

(a)

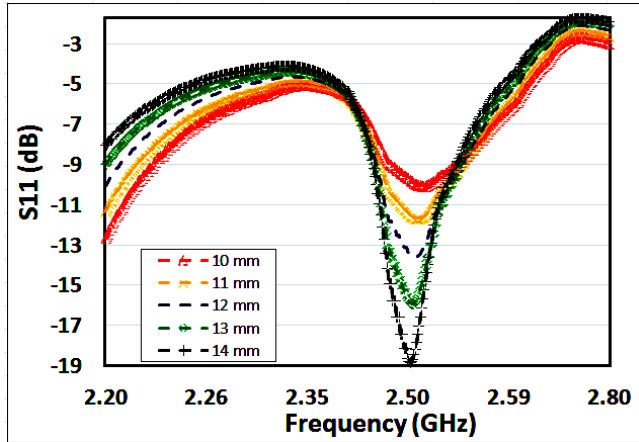

(b)

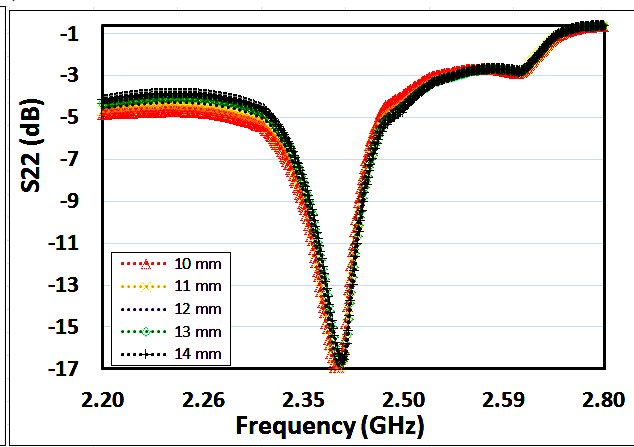

(c)

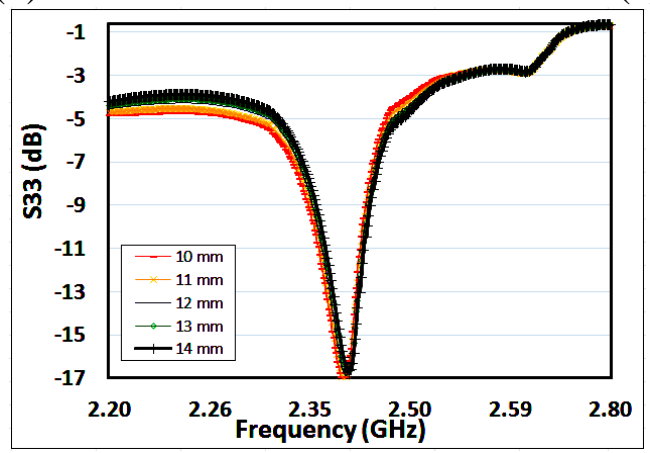

(d)

Figure 11. (a) $|\Gamma|$ responses (in $\mathrm{dB}$ ) and (b) S11, (c) S22, (d) S33 responses, as $W_{\text {center }}$ varies from $10 \mathrm{~mm}$ to $14 \mathrm{~mm}$. 
Similarly, the length of $S_{\text {center }}\left(L_{\text {center }}\right)$ is varied from $36 \mathrm{~mm}$ to $44 \mathrm{~mm}$ by an interval of $2 \mathrm{~mm}$. $W_{\text {center }}$ and the other parameters are maintained the same as in Table 2. The resulted $|\Gamma|$ response (in $\mathrm{dB}$ ) plotted in Figure 12(a) displays an evident decrease in frequency spacing between both resonances. As $L_{\text {center }}$ lengthens, both optimal resonant frequencies grow noticeably closer by 190 $\mathrm{MHz}$, from a spacing of $216 \mathrm{MHz}$ to a mere $26 \mathrm{MHz}$ away from each other. At the same time, the optimal high resonant frequency at Port 1 decreases from $2.604 \mathrm{GHz}$ to 2.423 $\mathrm{GHz}$, as shown in Figure 12(b). Viewing from its $|\Gamma|$ (in $\mathrm{dB}$ ) aspect however, the degree of matching at all three ports improves immensely. The optimal S11 reduces from $-12.31 \mathrm{~dB}$ to $-22.594 \mathrm{~dB}$ while the optimal $\mathrm{S} 22$ reduces from $-14.836 \mathrm{~dB}$ to $-28.009 \mathrm{~dB}$ and similarly, the optimal S33 reduces from $-14.842 \mathrm{~dB}$ to $-28.022 \mathrm{~dB}$.

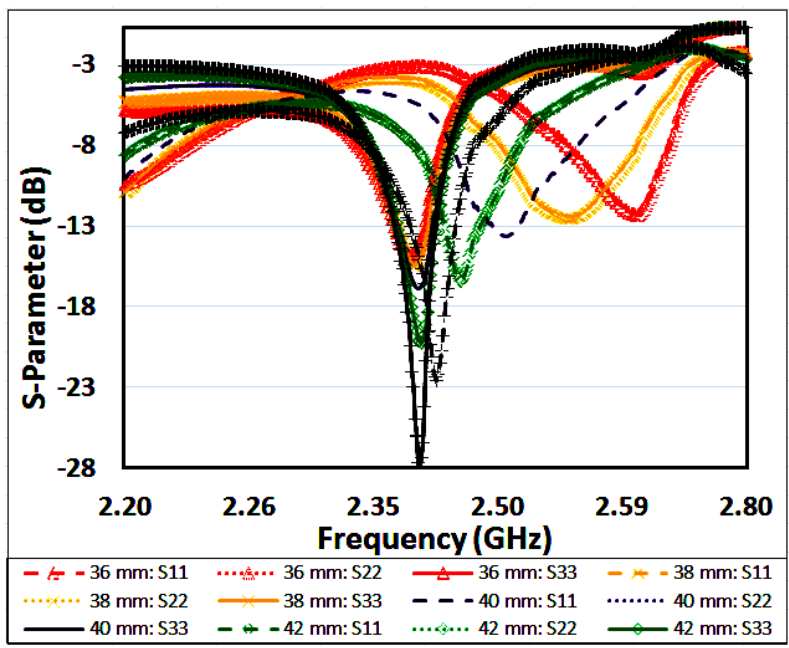

(a)

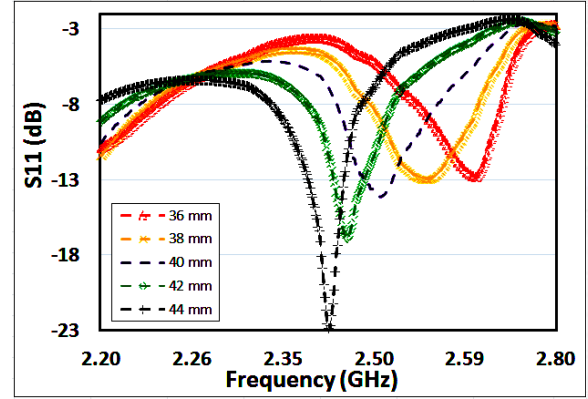

(b)

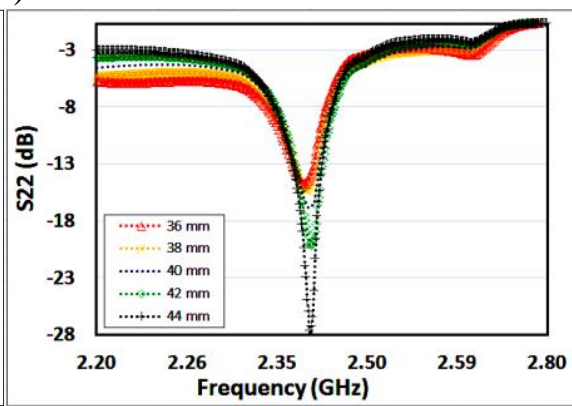

(c)

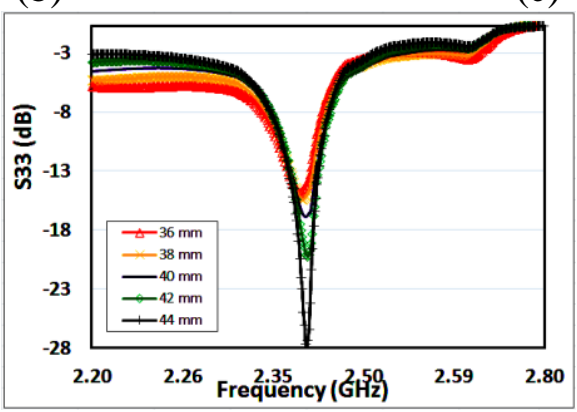

(d)

Figure 12. (a) $|\Gamma|$ responses (in $\mathrm{dB}$ ) and (b) $\mathrm{S} 11$, (c) $\mathrm{S} 22$, (d) $\mathrm{S} 33$ responses, as $L_{\text {center }}$ varies from $36 \mathrm{~mm}$ to $44 \mathrm{~mm}$. 


\subsection{Inset Slot}

The width of the slot $\left(W_{\text {slot }}\right)$ inset into the antenna is expanded by every $1 \mathrm{~mm}$ from $6.5 \mathrm{~mm}$ to $10.5 \mathrm{~mm}$ while the dimensions of the remaining parameters are maintained the same as in Table 2. Its $|\Gamma|$ responses (in $\mathrm{dB}$ ) are plotted in Figure 13. As $W_{\text {slot }}$ expands, the spacing between its optimal resonances reduces from $131 \mathrm{MHz}$ to $102 \mathrm{MHz}$ as illustrated in Figure 13(a). The change on the high resonant frequency at Port 1 is relatively minor compared to the low resonant frequency at Port 2 and 3. Precisely at Port 1, the optimal high resonant frequency merely increases by $14 \mathrm{MHz}$, from $2.503 \mathrm{GHz}$ to $2.517 \mathrm{GHz}$ as shown in Figure 13(b). On the other hand, the increase in the optimal low resonant frequency in Port 2 and 3 appears more obvious, that is by $43 \mathrm{MHz}$ from $2.372 \mathrm{GHz}$ to $2.415 \mathrm{GHz}$ respectively, as shown in Figure 13(c) and (d). Concurrently, the $|\Gamma|$ (in $\mathrm{dB}$ ) at its optimal resonances decrease at all three ports. S11 decreases from $-10.397 \mathrm{~dB}$ to $20.684 \mathrm{~dB}$ while S22 decreases from $13.744 \mathrm{~dB}$ to $-20.684 \mathrm{~dB}$ and S33 decreases from $-13.743 \mathrm{~dB}$ to $-20.672 \mathrm{~dB}$.

Varying $W_{\text {slot }}$ alters the reactive load on the radiating patch and subsequently affects the perturbation on its surface current. This manifests a conspicuous impact on the bandwidth of the antenna. Thereupon, the response of its 10 $\mathrm{dB}$ RL bandwidth is further studied as shown in Figure 14. It appears that the bandwidths exhibited at all three ports increase proportionally as $W_{\text {slot }}$ expands. Nevertheless, the increase at Port 1 is much substantial in spite of the minor increase in its high resonant frequency. In contrast, the increase in bandwidths exhibited at Port 2 and 3 are less drastic, which is from $51 \mathrm{MHz}$ to $81 \mathrm{MHz}$, respectively.

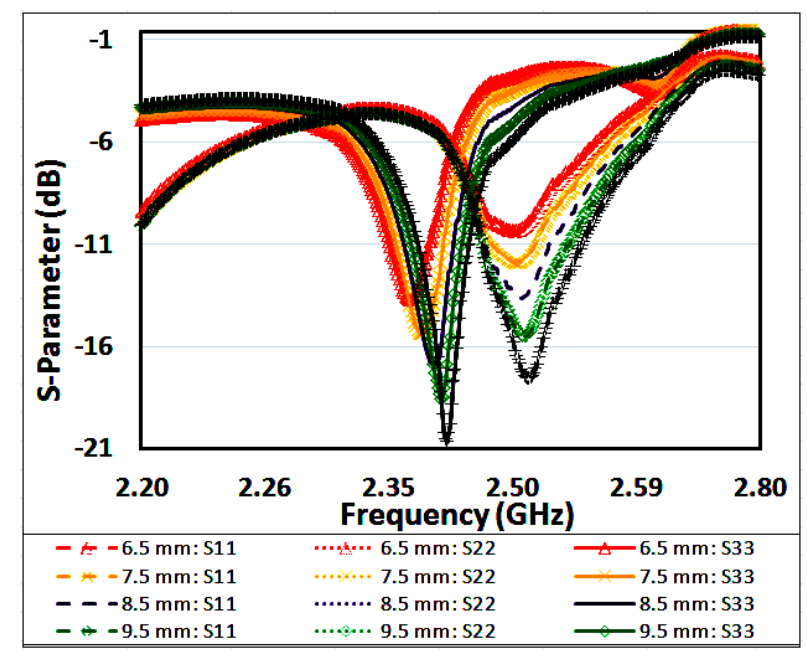

(a) 


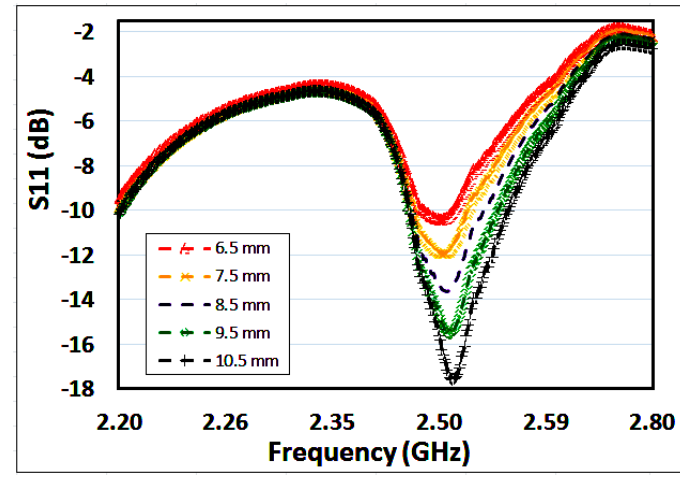

(b)

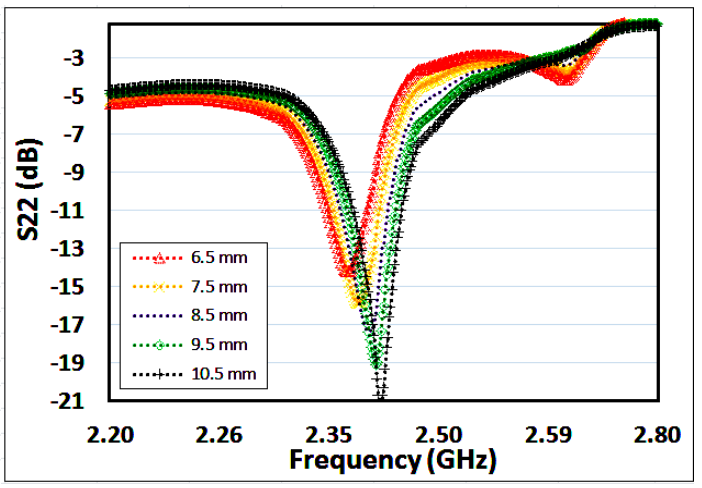

(c)

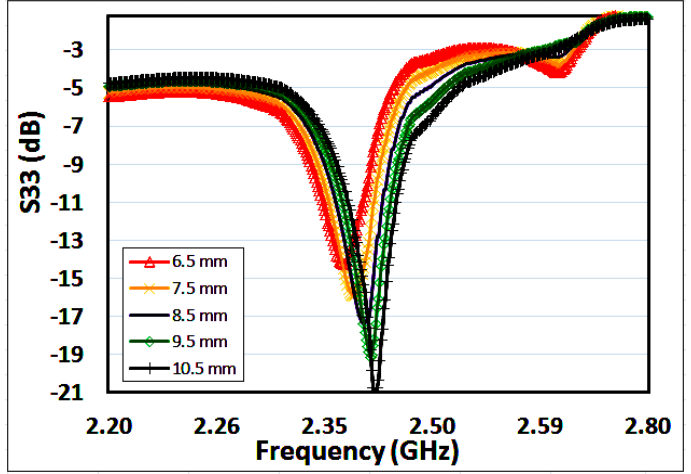

(d)

Figure 13. (a) $|\Gamma|$ responses (in $\mathrm{dB}$ ) and (b) S11, (c) S22, (d) S33 responses, as $W_{\text {slot }}$ varies from $6.5 \mathrm{~mm}$ to $10.5 \mathrm{~mm}$.

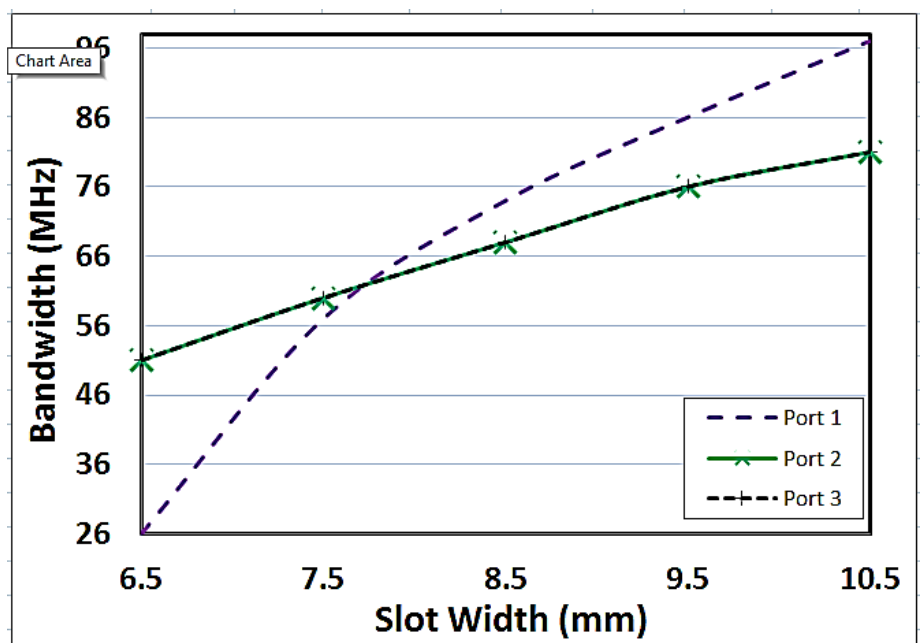

Figure 14. $10 \mathrm{~dB}$ RL bandwidth response as $W_{\text {slot }}$ varies from $6.5 \mathrm{~mm}$ to $10.5 \mathrm{~mm}$.

\section{RESULTS AND DISCUSSION}

The summary of the parametric study is depicted in Table 3. It shows the overall changes on the antenna performance when the dimensions of the E-shaped patch are varied accordingly. Both high and low resonances separate further apart when $L_{\text {dominant }}$ and $L_{\text {side }}$ increase respectively but the adverse occurs when the rest of the 
dimensions increase. Increasing $W_{\text {side }}$ tunes up the low resonant frequency at Port 2 and 3 , but increasing either $L_{\text {center }}$ or $W_{\text {center }}$ tunes down the high resonant frequency at Port 1. Correspondingly, the resonances at all three ports reduce as either $W_{\text {dominant }}$ or $L_{\text {dominant }}$ increases. The resonances also reduce as $L_{\text {side }}$ increases. In conjunction with this, widening the inset slots increase the low resonant frequency at Port 2 and 3 considerably and increase the high resonant frequency at Port 1 mildly.

Since $S_{\text {dominant }}$ governs the overall field configuration of the E-shaped patch antenna and $W_{\text {dominant }}$ is inversely

$$
\begin{aligned}
& E_{x}=-j \omega A_{002} \cos \left(\frac{2 \pi}{w} z^{\prime}\right), \\
& H_{y}=-\frac{2 \pi}{\mu w} A_{002} \sin \left(\frac{2 \pi}{w} z^{\prime}\right), \\
& E_{y}=E_{z}=H_{x}=H_{z}=0
\end{aligned}
$$

where the subscripts $x, y, z$ for $E$ and $H$ denote its respective $x, y, z$ direction. $A_{002}$ represents the amplitude coefficient of the $\mathrm{TM}_{002}$ mode whereas $z$ ' represents the field within the cavity. In conjunction with $E$ and

$$
\left(f_{r}\right)_{002}=\frac{1}{W \sqrt{\mu k}},
$$

which implies that the dominant resonant frequency is inversely proportional to the width of the patch, $W_{\text {dominant }}$ in this case. It is therefore sensible to note that the resonances decrease along with the expansion of $W_{\text {dominant }}$. proportional to its resonant frequency as expressed in (4), the decrease in both the resonances is thus reasonably anticipated along with the expansion of $W_{\text {dominant, }}$ as portrayed in Figure 7. This decrease in resonances could also be analyzed through the field configurations within the cavity model of the patch antenna. With the antenna operating in the $\mathrm{TM}_{002}$ mode, the distribution of its tangential electric field along the side walls of the cavity is as illustrated in Figure 1. Correspondingly, its electric field $(E)$ and magnetic field $(H)$ components are expressed with reference to the dimensions designated in Figure 1,

$H$, the resonant frequency $\left(f_{r}\right)$ at its dominant mode is expressed in terms of the dielectric permittivity $(\varepsilon)$ and permeability $(\mu)$ as

On the other hand, the decrease in both the resonances along with the elongation of $L_{\text {dominant }}$ in Figure 8 agrees with the expression in (2), which relates the resonant frequencies and $L_{\text {dominant }}$ in inverse 
proportionality. On top of this, the increasing trend observed for $|\Gamma|$ (in $\mathrm{dB}$ ) albeit the decrease in its resonances, suggests that the degree of mismatches at all three ports tend to intensify as $L_{\text {dominant }}$ elongates further.

Another interesting observation to be noted is the $\mathrm{S} 11$ response in Figure $8(\mathrm{~b})$, when $L_{\text {dominant }}$ is set at $32 \mathrm{~mm}$. A second lower resonance is observed at $2.224 \mathrm{GHz}$ with $\mathrm{S} 11$ of $-33.735 \mathrm{~dB}$. This is attributed to the additional series inductance $\left(\Delta L_{r}\right)$ effect, which not only influences the $S_{\text {side }}$, but throughout the entirety of the antenna. As stated in the E-shaped antenna segmentation, every section is inter-related and its current is continuously distributed throughout. Indeed, when $L_{\text {dominant }}$ is tuned remarkably short at $32 \mathrm{~mm}, \Delta L_{r}$ resulted by the current circumnavigation around the slot is sufficiently low to produce an obvious second resonance that is closely distanced from its initial resonance. As $L_{\text {dominant }}$ increases, the second resonance starts to shift lower but distanced much closer to its initial resonance, until to a point that both resonances coupled together into one. It is thus found that only a single resonance is observed in Port 1 for $L_{\text {dominant }}$ of considerable length, approximately more than $33 \mathrm{~mm}$.

In Figure 9(c) and (d), the gradual changes in terms of resonances and $|\Gamma|$ (in $\mathrm{dB}$ ) observed when $W_{\text {side }}$ expands affirm the role of $S_{\text {side }}$ in tuning the antenna resonances at Port 2 and 3 with finer precision. On the other hand, elongating $L_{\text {side }}$ increases the additional series inductance $\left(\Delta L_{r}\right)$ because the diversion of surface current around the slots is more intensive. Hence, the low resonant frequency at Port 2 and 3 decrease significantly, as observed in Figure 10(c) and (d). Apart from this, it is also noted that the response observed in Figure 10(b) when
$L_{\text {side }}$ is set at $23 \mathrm{~mm}$ is alike to the $\mathrm{S} 11$ response observed when $L_{\text {dominant }}$ is set at 32 $\mathrm{mm}$. A second resonant mode at Port 1 is observed at $2.223 \mathrm{GHz}$ with $\mathrm{S} 11$ of -31.306 $\mathrm{dB}$. This is again, due to the parasitic $\Delta L_{r}$, which tunes a second resonance that is 332 $\mathrm{MHz}$ lower than its initial resonant mode. Nevertheless, as $L_{\text {side }}$ increases, both resonances ultimately couple into one single band.

The responses observed during the variations of the dimension for $S_{\text {center }}$ is similar as that for $S_{\text {side }}$. The insignificant change in resonances observed during the expansion of $W_{\text {center }}$ in Figure 11(b), affirms the function for $S_{\text {center }}$ that fine tunes the antenna resonance at Port 1 with higher accuracy. The elongation of $L_{\text {center }}$ introduces the additional series inductance $\left(\Delta L_{r}\right)$ to the initial patch inductance $\left(L_{r}\right)$ at Port 1 due to the extension of its current path. Consequently, this impacted the descent of the optimal high resonance at Port 1, as shown in Figure 12(b). Since the low resonance at Port 2 and 3 are primarily attributed to the current flow circumnavigating around the slots, there is no significant change caused by the variation of $L_{\text {center }}$, as mutually portrayed in Figure 12(c) and (d). The decrease of $|\Gamma|$ (in $\mathrm{dB}$ ) observed as $L_{\text {center }}$ is elongated reflects a sheer contrast to the $|\Gamma|$ (in $\mathrm{dB}$ ) responded from the elongation of $L_{\text {dominant }}$ and $L_{\text {side }}$. Its effect is therefore useful in counter balancing the mismatches caused.

When expanding $W_{\text {slot }}$, the high resonant frequency only undergoes a minor increase as observed in Figure 13(b). This is due to the amplitude of the current circumnavigating around the slots that is literally the same as that at the edges of the E-shaped patch during high resonance. Consequently, the current flow is somewhat similar to the flow of a basic rectangular patch. In contrast, a much significant 
increase is observed at its low resonant frequency, as depicted in Figure 13(c) and (d). The expansion on $W_{\text {slot }}$ causes $S_{\text {side }}$ and $S_{\text {center }}$ parted further away from each other, distanced by the substrate embraced in

$$
C=\varepsilon_{\mathrm{r}} \varepsilon_{0} \frac{A}{d}
$$

where $\varepsilon_{o}$ is the permittivity in free space $(8.854 \mathrm{pF} / \mathrm{m}), A$ is the surface area of the cofacing conductive plates, and $d$ denotes the plates separation, which is $W_{\text {slot }}$ in this context. As such, $\Delta C_{r}$ decreases as $W_{\text {slot }}$ widens. In response, the low resonant frequency increases proportionally, as depicted in Figure 13(c) and (d). This explication agrees well with the dual-LC circuit model, where the lower resonance is closely associated with $\Delta C_{r}$.

$$
\frac{\delta \omega}{w_{0}}=-\frac{\iint_{V_{0}}\left(\Delta \varepsilon E^{\cdot} E_{0}^{*}+\Delta \mu E^{\cdot} E_{0}^{*}\right) d V}{\iint_{V_{0}}\left(\varepsilon E^{\cdot} E_{0}^{*}+\mu E^{\prime} \cdot E_{0}^{*}\right) d V}
$$

where $\delta \omega$ is the change in angular resonant frequency, $\omega_{0}$ is the angular resonant frequency of the original cavity (the angular resonant frequency of the rectangular patch, in this case), $\Delta \varepsilon$ and $\Delta \mu$ are the respective change in $\varepsilon$ and $\mu, \bar{E}_{0}$ and $\bar{H}_{0}$ are the fields of the original cavity (the basic rectangular patch antenna, in this case), $\bar{E}$ and $\bar{H}$ are the fields of the perturbed cavity (the E-shaped patch antenna, in this case), and $V_{0}$ is the volume of the cavity. Expression (9) simply

$$
\begin{aligned}
& \frac{\Delta \omega}{\omega_{0}}=\frac{\Delta W_{\mathrm{m}}+\Delta W_{a}}{W_{m}+W_{a}}, \\
& Q_{n}=\omega_{0} \frac{W_{m}+W_{s}}{P_{n}}
\end{aligned}
$$
(Waldron, increase as observed in Figure 13. 2012)

between. The resultant effect is the reduction of the parallel parasitic capacitance $\left(\Delta C_{r}\right)$. The logic behind this could be further illustrated base on the fundamental capacitor formulation, with capacitance $(C)$ given as

The increase of the resonant frequencies along with the expansion of $W_{\text {slot }}$ can also be visualized from the cavity model of the patch antenna. Base on the cavity perturbation theory, when a resonant cavity is perturbed, in this case when the inset slots perturb the rectangular patch to form the Eshaped patch, the electromagnetic (EM) fields inside the cavity change accordingly. This results in the resonant frequency shifts (Jaheen et al., 2016), which is expressed as

1960)

implicates that as $W_{\text {slot }}$ widens, the perturbation caused by the inset slots intensifies. This leads to the decrease in $\varepsilon$ and $\mu$, hence the resonant frequencies

In fact, $\delta \omega$ and the quality factor of its resonant mode $\left(Q_{n}\right)$ are intimately related to the total stored energy $\left(W_{m}+W_{\theta}\right)$ within the cavity, given as (Omar, 2011; Pozar, 
where $\Delta W_{m}$ and $\Delta W_{\theta}$ are the changes in the stored magnetic energy and electric energy, respectively, and $P_{n}$ is the average power loss. It is thus noted that the $\left(W_{m}+W_{e}\right)$ is lessened along with the increase in $\omega_{0}$ 's.
This in turn, explains the increase in bandwidths observed in Figure 14, since the spectral lines are broadened as $Q_{n}$ is lowered.

Table 3. Summary of parametric study for the E-shaped antenna.

\begin{tabular}{ccccccc}
\hline & Ports & \multicolumn{2}{c}{1} & & 2,3 & \multirow{2}{*}{$\begin{array}{c}\text { Frequency } \\
\text { Spacing }\end{array}$} \\
\cline { 2 - 6 } & Parameters & $|\Gamma|$ & $f_{r}$ & $|\Gamma|$ & $f_{r}$ & Spacing \\
Width $\uparrow$ & $S_{\text {dominant }}$ & $\uparrow$ & $\downarrow$ & $\mathrm{NC}$ & $\downarrow$ & \\
& $S_{\text {side }}$ & $\mathrm{NC}$ & $\mathrm{NC}$ & $\mathrm{NC}$ & $\uparrow$ & \\
& $S_{\text {center }}$ & $\uparrow$ & $\downarrow$ & $\mathrm{NC}$ & $\mathrm{NC}$ & $\downarrow$ \\
Length & Slot & $\uparrow$ & $\uparrow$ & $\uparrow$ & $\uparrow$ & $\downarrow$ \\
$\uparrow$ & $S_{\text {dominant }}$ & $\downarrow$ & $\downarrow$ & $\downarrow$ & $\downarrow$ & $\uparrow$ \\
& $S_{\text {side }}$ & $\downarrow$ & $\downarrow$ & $\downarrow$ & $\downarrow$ & $\uparrow$ \\
& $S_{\text {center }}$ & $\uparrow$ & $\downarrow$ & $\uparrow$ & $\mathrm{NC}$ & $\downarrow$
\end{tabular}

Note:

increases

decreases

NC no significant change observed

\section{CONCLUSION}

In this paper, an E-shaped patch antenna is designed to operate in the $2.4-\mathrm{GHz}$ ISM band. It supports resonances of $2.5 \mathrm{GHz}$ at its center port (Port 1) and $2.4 \mathrm{GHz}$ at its side ports (Port 2, 3). At Port 1, its measured optimal $|\Gamma|$ (in $\mathrm{dB}$ ) is $-16.2 \mathrm{~dB}$ while at Port 2 , it is $-17.5 \mathrm{~dB}$ and at Port 3 , it is $-18.6 \mathrm{~dB}$. In general, the analysis elucidates the effects contributed by the various dimensional parameters. It provides a comprehensive guide on the design and optimization of the antenna at the 2.4-GHz ISM band. By adjusting the geometrical dimensions according to the observations summarized in Table 3, one could easily tune the dual resonances of the E-shaped patch antenna to realize the permissible range as specified by the relevant country regulations. The manipulation of this analysis thus reduces the dependence on random trial, which tends to be clueless mostly. This way, the design cycle could be vastly expedited. 


\section{ACKNOWLEDGEMENTS}

The authors would like to thank Auto ID Lab (AIDL), School of Electrical and Electronic Engineering, Universiti Sains Malaysia (USM) for providing the opportunity and support on the research through RUI grant (814241).

\section{REFERENCES}

Ang B.-K. \& Chung B.-K. (2007). A wideband E-shaped microstrip patch antenna for 5-6 GHz wireless communications. Progress In Electromagnetics Research, 75: 397407.

Ao W. \& Xiang W.Q. (2013). Analysis and design of E-shaped dual-frequency microstrip antenna based on CPSO algorithm. In: Satapathy S.C., Raju K.S., Mandal J.K. \& Bhateja V. (eds.): Proceedings of the Second International Conference on Computer Science and Electronics Engineering, Hangzhou, 2223 March, pp. 3016-3019, Chenai, India: Springer.

Balanis C.A. (2005). Antenna Theory, Analysis and Design, pp. 831, New York, USA: John Wiley and Sons.

Bayat A. (2012). Single patch E-shaped compact microstrip antenna. International Journal of Modern Engineering Research, 2: 3895-3898.

Chen Y., Yang S. \& Nie Z. (2010). Bandwidth enhancement method for low profile E-shaped microstrip patch antennas. IEEE Transactions on Antennas and Propagation, 58: 24422447.

Coleman D.D. \& Westcott D.A. (2012). CWNA: Certified Wireless Network
Administrator Official Study Guide, pp. 192, New York, USA: John Wiley \& Sons.

Ghannay N. \& Samet A. (2009). E-shaped patch antenna modeling with MoM and RWG basis functions. In: 16th International Conference on Electronics, Circuits, and Systems, Yasmine Hammarmet, 13-16 December, pp. 199202, New York, USA: IEEE.

Hammerstad E.O. (1975). Equations for microstrip circuit design. In: Proceedings of the 5th European Microwave Conference, Hamburg, 1-4 September, pp. 268-272, New York, USA: IEEE.

IEEE Computer Society (2012). Wireless LAN Medium Access Control (MAC) and Physical Layer (PHY) Specifications, pp. 1442-1535, New York, USA: IEEE Standard Association.

International Telecommunication Union (1947). Documents of the International Radio Conference Doc. No. 1-100, pp. 628, Atlantic City, USA: Bureau of the International Telecommunication Union.

Islam M.T., Shakib M.N. \& Misran N. (2009a). Broadband E-H shaped microstrip patch antenna for wireless systems. Progress In Electromagnetics Research, 98: 163-173.

Islam M.T., Shakib M.N., Misran N. \& Yatim B. (2009b). Modified E-H shaped microstrip antenna for wireless systems. In: Proceedings of the 2009 IEEE International Conference on Networking, Sensing and Control, Okayama, 26-29 March, pp.794-796, New York, USA: IEEE. 
Jaheen F., Ovi A.A.N. \& Akhi M. (2016). Slot loaded square microstrip patch antenna for dual band operation. Electrical and Electronic Engineering, 6: 11-17.

Jain N., Nema R., Khare A. \& Gour P. (2011). Dual band E-shape microstrip patch antenna on RT DUROID 5880 substrate for pervasive wireless communication. International Journal of Computer Science and Information Technologies, 2: 1075-1081.

Jalali M., Sedghi T. \& Shafei S. (2014). Design and implementation of low profile antenna for dual-band applications of using rotated E-shaped conductor-backed plane. The Scientific World Journal, 2014: 1-5.

Kadu M.B., Labade R.P. \& Nandgaonkar A.B. (2012). Analysis and designing of E-shape microstrip patch antenna for MIMO application. International Journal of Engineering and Innovative Technology, 1: 67-69.

Khidre A., Lee K.F., Yang F. \& Elsherbeni A. (2010). Wideband circularly polarized E-shaped patch antenna for wireless applications. IEEE Antennas and Propagation Magazine, 52: 219 229.

Kumar G. \& Gupta K.C. (1985). Nonradiating edges and four edges gap coupled multiple resonator broadband microstrip antennas. IEEE Transactions on Antennas and Propagation, 33: 173178.

Lee K.F. \& Chen W. (1997). Advances in Microstrip and Printed Antennas, pp. 53-62, New York, USA: Wiley.
Munson R.E. (1974). Conformal microstrip antennas and microstrip phased arrays. IEEE Transactions on Antennas and Propagation, 22: 74-78.

Nazabal J.A., Iturri P.L., Azpilicueta L., Falcone F. \& Fernandez-Valdivielso C. (2012). Performance analysis of IEEE 802.15.4 compliant wireless devices for heterogeneous indoor home automation environments. International Journal of Antennas and Propagation, 2012: 1-14.

Omar A. (2011). Electromagnetic Scattering and Material Characterization, pp. 710, Norwood, MA: Artech House.

Pandey V.K. \& Vishvakarma B.R. (2007). Analysis of an E-shaped patch antenna. Microwave and Optical Technology Letters, 49: 4-7.

Patel S.K. \& Kosta Y.P. (2011). E-shape microstrip patch antenna design for GPS application. In: International Conference on Current Trends in Technology, Gujarat, 8-10 December, pp. 1-4, New York, USA: IEEE.

Pozar D.M. (2012). Microwave Engineering. 4th edition, pp. 306-312, New York, USA: John Wiley and Sons.

Razzaqi A.A., Mustaqim M. \& Khawaja B.A. (2013). Wideband E-shaped antenna design for WLAN applications. In: IEEE 9th International Conference on Emerging Technologies, Islamabad, 5-6 Septermber, pp. 1-6, New York, USA: IEEE.

Saha S.K., Rony A.I., Suma U.H. \& Rahman M.M. (2013). E-shape microstrip patch antenna design for wireless applications. International 
Journal of Science, Engineering and Technology Research, 2: 625-632.

Waldron R.A. (1960). Perturbation theory of resonant cavities. In: Proceedings of the Institution of Electrical Engineers, 22 July, pp. 272-274, London, UK: IET.

Yang F., Zhang X.-X. \& Rahmat-Samii Y. (2001). Wide-band E-shaped patch antennas for wireless communications.
IEEE Transactions on Antennas and Propagation, 49: 1094-1100.

Zurcher J.F. \& Gardiol F. E. (1995). Broadband Patch Antennas, Boston, USA: Artech House.

Zyren J. \& Petrick A. (1999). Brief Tutorial on IEEE 802.11 Wireless LANs, pp. 1-7, Florida, USA: Intersil Corp 